\title{
Cardiac Ventriculography
}

National Cancer Institute

\section{Source}

National Cancer Institute. Cardiac Ventriculography. NCI Thesaurus. Code C124142.

A medical imaging test that involves injecting contrast media into the heart's ventricle(s)

to determine a patient's cardiac function. 